BMC

Pregnancy \& Childbirth

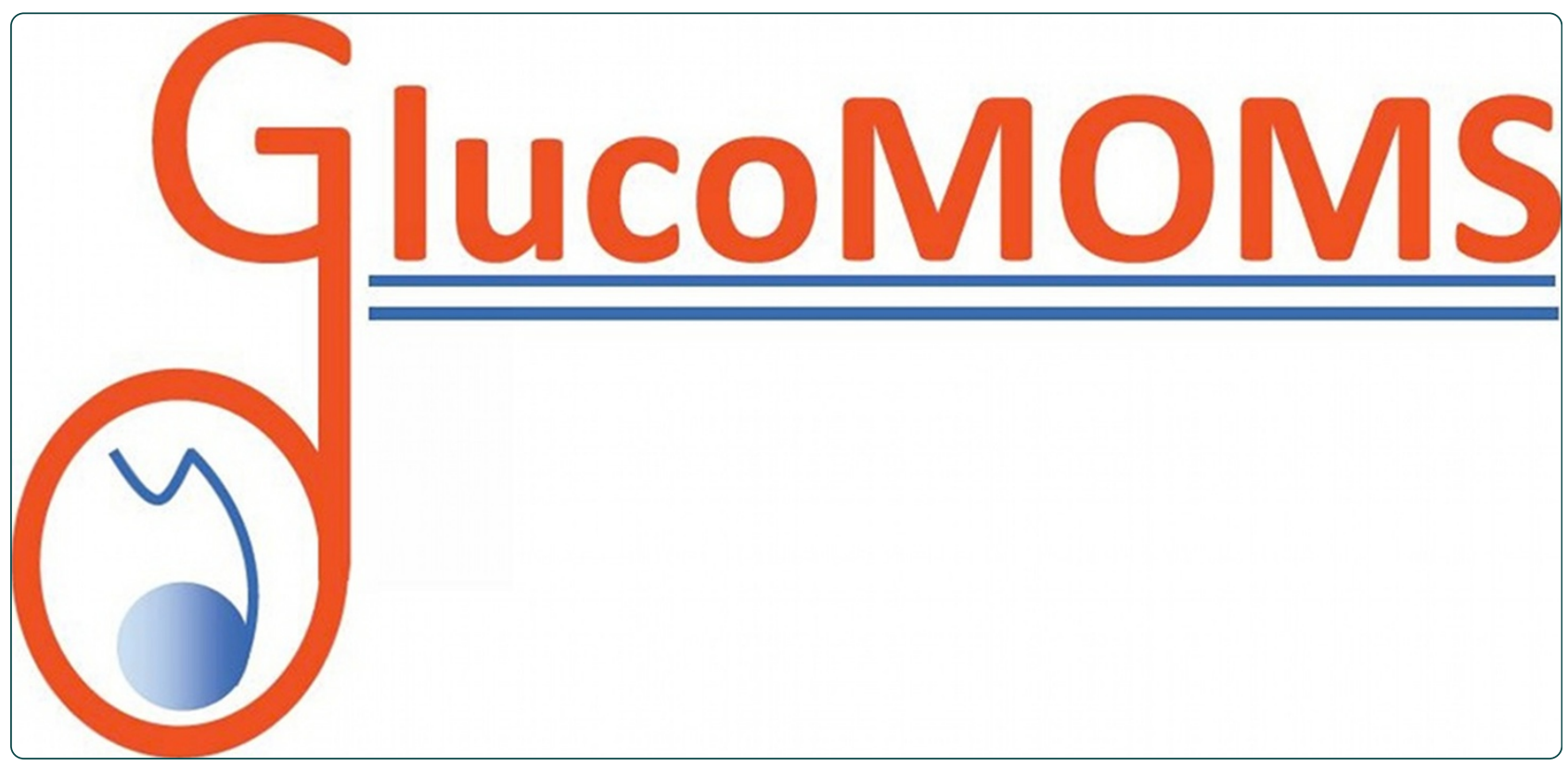

Effectiveness of continuous glucose monitoring during diabetic pregnancy (GlucoMOMS trial); a randomised controlled trial

Voormolen et al.

() Biomed Central

Voormolen et al. BMC Pregnancy and Childbirth 2012, 12:164 http://www.biomedcentral.com/1471-2393/12/164 


\title{
Effectiveness of continuous glucose monitoring during diabetic pregnancy (GlucoMOMS trial); a randomised controlled trial
}

\author{
Daphne N Voormolen ${ }^{1 *}$, J Hans DeVries ${ }^{2}$, Arie Franx ${ }^{1}$, Ben WJ Mol ${ }^{3,4}$ and Inge M Evers ${ }^{5}$
}

\begin{abstract}
Background: Hyperglycemia in pregnancy is associated with poor perinatal outcome. Even if pregnant women with diabetes are monitored according to current guidelines, they do much worse than their normoglycaemic counterparts, marked by increased risks of pre-eclampsia, macrosomia, and caesarean section amongst others. Continuous Glucose Monitoring (CGM) is a new method providing detailed information on daily fluctuations, used to optimize glucose control. Whether this tool improves pregnancy outcome remains unclear. In the present protocol, we aim to assess the effect of CGM use in diabetic pregnancies on pregnancy outcome.

Methods/design: The GlucoMOMS trial is a multicenter open label randomized clinical trial with a decision and cost-effectiveness study alongside. Pregnant women aged 18 and over with either diabetes mellitus type 1 or 2 on insulin therapy or with gestational diabetes requiring insulin therapy before 30 weeks of gestation will be asked to participate. Consenting women will be randomly allocated to either usual care or complementary CGM. All women will determine their glycaemic control by self-monitoring of blood glucose levels and HbA1c. In addition, women allocated to CGM will use it for 5-7 days every six weeks. Based on their CGM profiles they receive dietary advice and insulin therapy adjustments if necessary. The primary outcome measure is rate of macrosomia, defined as a birth weight above the 90th centile. Secondary outcome measures will be birth weight, composite neonatal morbidity, maternal outcome and costs. The analyses will be according to the intention to treat principle.
\end{abstract}

Discussion: With this trial we aim at clarifying whether the CGM improves pregnancy outcome when used during diabetic pregnancies.

Trial registration: Nederlands Trial Register: NTR2996

Keywords: Diabetes, Pregnancy, Continuous glucose monitor, Macrosomia, Effectiveness

\section{Background}

Diabetes during pregnancy is a high risk situation for both mother and the child. Optimising glycaemic control is a key feature of prenatal care for diabetic women [1]. Since the 1960s, there has been a reduction in perinatal morbidity and mortality $[2,3]$. However, even if pregnant women with diabetes are monitored according to current guidelines, they do much worse than their normoglycaemic counterparts. In a nationwide study in 2000 on the outcome of 323 women with a pregnancy complicated by type 1 diabetes

\footnotetext{
* Correspondence: d.p.vanmunster-2@umcutrecht.nl

'Department of Obstetrics and Gynaecology, University Medical Centre Utrecht, Utrecht, the Netherlands

Full list of author information is available at the end of the article
}

we found a high prevalence of maternal, perinatal and neonatal complications [4]. These complications occurred despite good pre-pregnancy care, as $84 \%$ of these pregnancies were planned and $70 \%$ used adequate folic acid supplementation. Overall, glycaemic control during these pregnancies was acceptable, as average $\mathrm{HbA1c}$ value was $44 \mathrm{mmol} / \mathrm{mol}$. Nevertheless, these pregnancies showed high complications rates that require improvement.

The continuous glucose monitoring system (CGMS) is a new technique that retrospectively provides detailed information regarding glucose fluctuations during the day. The CGMS has been studied in non-pregnant patients where it has demonstrated clinical usefulness by enhancing decision-making through detecting previously 
unrecognised postprandial hyperglycaemia and nocturnal hyper-and hypoglycemia [5]. Scientific evidence on a HbA1c-reducing effect of CGMS use is limited [6,7]. Although some studies do evaluate the effect of CGMS use on biochemical endpoints, such as HbAlc levels, data on clinical endpoints like diabetic complications, are lacking. The usefulness of CGMS use during pregnancy has hardly been evaluated up to now [7]. A recent RCT showed that intermittent CGMS use during pregnancy in 71 women with pre-existing diabetes resulted in a significant reduction in HbA1c at 32-36 weeks gestation. Furthermore, the odds ratio for reduced risk of macrosomia was 0.36 (95\% CI 0.13-0.98, p $=0.05)$ [8]. However, this study was hampered by small sample size and both study groups differed in composition (e.g. 5 set of twins in the intervention group as opposed to none in the control group). Furthermore 11 (4\%) of the children in the intervention group were small for gestational age ( $\leq 10$ centile) as opposed to none in the control group. This difference did not reach statistical significance either but may point to an adverse effect of CGMS. Another recent RCT by Secher et al. investigated the effect of intermittent real time CGMS use during pregnancy in 154 women with pre-existing diabetes on pregnancy outcome [9]. The rate of macrosomia was not significantly different between the intervention group (43\%) and the control group $(30 \%)(p=0.09)$. Also, HbA1c levels were similar in both groups. The investigators concluded that intermittent CGMS use did not improve glycaemic control in pregnancy nor did it improve pregnancy outcome. Thus, further evaluation in larger studies is urgently needed before wide implementation of CGMS during pregnancy.

\section{Relevance}

Despite improvements in blood glucose monitoring technology, and obstetric and neonatal care over the last decades, maternal and fetal complications occur much more frequent in diabetic women than in non-diabetic women [4]. Our Dutch nationwide study of type 1 diabetes mellitus in pregnancy showed high complication rates in diabetes pregnancies. Maternal complications were episodes of severe hypoglycemia (40\%), preeclampsia (13\%) and caesarean section (44\%). Perinatal and neonatal complications included congenital malformations (9\%), prematurity (32\%), perinatal mortality (3\%), macrosomia (45\%) and neonatal morbidity such as shoulder dystocia (14\%), all remarkably higher rates than those in non-diabetic pregnancies [4]. Similar rates of complications have recently been found in other nationwide studies in Denmark, the United Kingdom and Sweden [10-12]. In the Dutch study $45 \%$ of the newborns were macrosomic and $24 \%$ were extremely macrosomic (>p97.7). Recent data from Denmark show that $56 \%$ of the newborns of type 2 diabetic women were macrosomic [11].

The prevalence of gestational diabetes is increasing and comprises approximately $5 \%$ of the pregnant women. Given the worldwide rising incidence of diabetes, as a consequence of changed life style and consequent obesity, improvement of obstetric care for diabetic patients is essential $[13,14]$. Moreover, it has been shown that children born macrosomic are at risk for developing obesity and diabetes mellitus type 2 at a young age [15-17]. Reduction of macrosomia will not only reduce the risk of perinatal complications but may also prevent these future health problems.

\section{Methods/design \\ Aims}

This trial evaluates the clinical effectiveness, costs and cost-effectiveness of CGMS use with the aim to optimize glycaemic control and pregnancy outcome of diabetic pregnancies relative to standard control methods. The primary outcome measure is macrosomia. Secondary obstetric outcome measures are birth weight, neonatal and maternal morbidity. Furthermore, diabetic outcome measures are $\mathrm{HbA1c}$ level, and glucose variability. In addition, cost-effectiveness will also be evaluated.

\section{Study design}

The study will be a multicentre randomised controlled trial comparing standard care to standard care with additional CGMS use. The study will be open, as it is impossible to blind the pregnant women and health care workers involved for the strategy to which the women are allocated. This trial is performed by the Dutch Obstetric Consortium, a collaboration of the majority of hospitals in the Netherlands. It supplies research nurses and online services, and is supported by the Dutch Society of Obstetrics and Gynaecology. Approximately 25 hospitals, including university hospitals, teaching hospitals and non-teaching hospitals will participate in this trial.

The study has been approved by the ethics committee of the Academic Medical Centre Amsterdam (reference number 10/322 \# 11.17.0554) and in addition by the boards of management of all participating hospitals.

\section{Participants}

Pregnant women with pre-existing diabetes mellitus (type 1 or 2) before gestational age of 16 weeks or with gestational diabetes requiring insulin therapy before 30 weeks gestational age will be asked to participate. Inclusion criteria include maternal age of at least 18 years and need for insulin treatment by means of injections or insulin pump. Patients with severe medical or psychological comorbidity will be excluded. Multiple pregnancies will 
also be excluded since they require different standards of obstetric evaluation.

\section{Recruitment and randomisation}

Potential study candidates will be identified by their gynaecologist or internist. Patients eligible for participation in the study will be invited for additional counselling by a research nurse, to ensure that they will be fully informed on the nature of the study by means of both oral and written information. Patients who agree to participate will be asked to sign a written informed consent of which they will receive a copy.

After providing informed consent for the participation in the study, the patient will be randomly allocated to either standard care or standard care and additional CGMS use. Randomisation will be done on a 1:1 basis over the internet, stratified for type of diabetes, using a web-based program. The current inclusion status is being displayed on the GlucoMOMS trial website http://www.studies-obsgyn. nl/glucomoms/page.asp?page_id=1027

\section{Hypothesis}

The CGMS has been shown to potentially improve glycaemic control as defined by HbA1c levels. Since obstetric complications in diabetic pregnancies, especially macrosomia, seem to be related to glycaemic control, we hypothesise that the additional use of CGMS will reduce the macrosomia rate by 30 percent.

\section{Intervention}

The continuous glucose monitoring system (CGMS) is a new technique that is efficacious in the monitoring of diabetic women. It can provide a comprehensive glucose profile over a 5-7 days period. The CGMS (CGMS Medtronic: Minimed, Northridge,CA) measures glucose levels through electro-chemical detection in the extracellular fluid of the abdominal subcutaneous tissue and stores values in a range of $2.2-22.2 \mathrm{mmol} / \mathrm{L}$ every $10 \mathrm{sec}$. An average value is stored in the monitor every 5 minutes, providing up to 288 blood glucose measurements $(12 \times 24)$ a day. The subjects are unaware of the results of the sensor measurements during monitoring and need to continue self-monitoring of blood glucose while carrying the monitor. After 5-7 days glucose profiles are obtained from the monitor and can be evaluated by the diabetologist and dietary or insulin therapy changes can be advised.

All study participants will determine their glycaemic control by self-monitoring of blood glucose levels (4-8 times/day) and HbA1c-levels (every 4 weeks) throughout the course of pregnancy. Figure 1 represents a flowchart of the study.

\section{Outcome measures}

\section{Main study parameter/endpoint}

Outcome measures of the trial are related to obstetric complications and glycaemic control. Macrosomia is the most frequent complication of diabetes during pregnancy and is associated with neonatal morbidity and long term effects. Therefore, the primary outcome measure is macrosomia rate. Macrosomia is defined as a birth weight above the $90^{\text {th }}$ centile.

Secondary maternal endpoints are: pre-eclampsia (defined as systolic blood pressure $\geq 140 \mathrm{mmHg}$ or diastolic blood pressure $\geq 90 \mathrm{mmHg}$ occurring after 20 weeks of gestation and simultaneous proteinuria of $\geq 300 \mathrm{mg} / 24$ hours) caesarean section, hypoglycemia (subdivided as biochemical hypoglycemia (self-measured blood glucose $<3.9 \mathrm{mmol} / \mathrm{l}$ ) or symptomatic hypoglycemia (symptoms of hypoglycemia confirmed by self-measured blood glucose $<3.9 \mathrm{mmol} / \mathrm{l}$ ) or severe hypoglycemia, (prompting the need for help by another person)), HbA1c levels throughout the course of pregnancy, glucose variability (Mean Absolute Glucose change per patient per hour) and relative glucose variability (Coefficient of Variability) [18].

Secondary neonatal endpoints are: birth weight, preterm birth, perinatal death, birth trauma (including shoulderdystocia, clavicle fracture or Erb's palsy), neonatal hypoglycemia (defined as blood glucose $<2.6 \mathrm{mmol} / \mathrm{l}$ ), respiratory distress syndrome (RDS), broncho pulmonal dysplasia (BPD), intraventricular haemorrhage II B or worse, necrotizing enterocolitis (NEC), and sepsis.

\section{Follow up}

Long term follow up of the offspring is desirable as long term effects of diabetic pregnancy on infants, in particular those born macrosomic, have become evident. Long term follow up is planned but will depend on future funding.

\section{Economic evaluation / cost analysis}

With two or three continuous glucose monitors (hardware), costing about $€ 1,500$ each, the total monitor costs are $€ 37,500$ per centre. We will use 5 sensors (each $€ 50$ ) per pregnancy, resulting in sensor costs of $€ 37,500$, bringing total equipment costs at $€ 75,000$. The additional costs of CGMS per year (per pregnancy) are $€ 500$. With these crude estimates, a hypothesized $33 \%$ reduction in macrosomia rate, would imply for the short term a cost-effectiveness ratio of $€ 1,500$ per prevented case of macrosomia, $€ 6,076$ per prevented caesarean section, $€ 15,189$ per prevented case of preterm birth, and $€ 48,605$ per prevented case of neonatal death. A strong reduction of macrosomia would also reduce downstream resource use and associated costs of neonatal complications. The question is to what extent downstream economic benefits also offset the costs required to obtain 


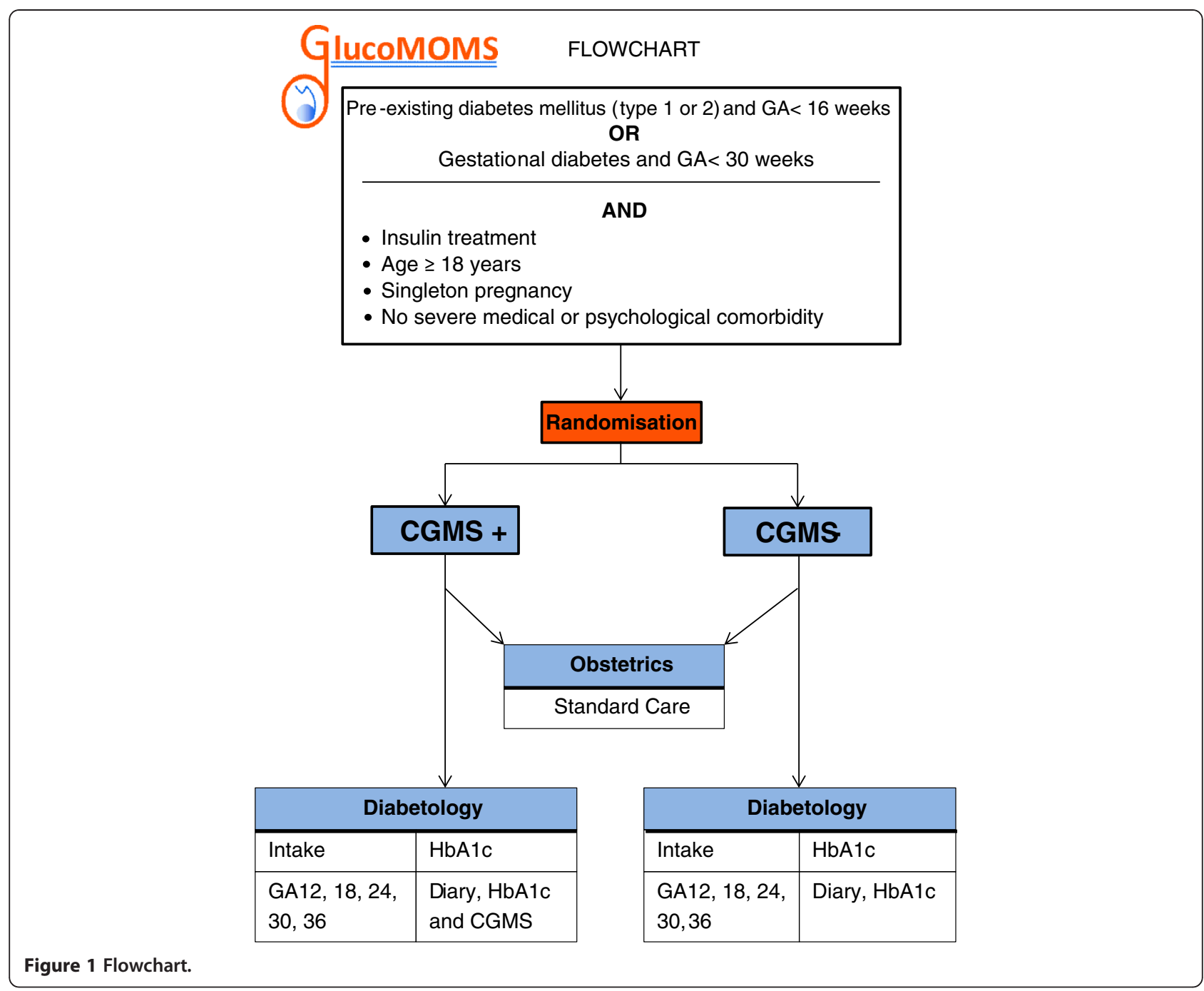

these clinical outcomes, and whether the resulting costto-benefit ratio justifies a standard policy of using CGMS during pregnancy $[19,20]$.

Rising health care costs and reimbursement of expensive medical devices are not justified unless extensive costeffective analysis turns out favourable. Therefore, besides evaluation of the effectiveness of CGMS on pregnancy outcome, resource utilization and costs for maternal and neonatal care will be analysed as well.

\section{Statistics}

\section{Sample size}

We anticipate that a reduction of macrosomia from $45 \%$ to $30 \%$ will outweigh the costs of the additional use of the CGMS. As we assume $10 \%$ protocol violations and drop out, we need to randomise 300 women (Alpha-error .05, Beta-error .20, one-sided test) of which 150 will receive additional CGMS use and 150 will be controls.

\section{Data analysis}

Data will initially be analysed according to the intention to treat method. The main outcome variable, macrosomia, will be assessed by calculating rates in the two groups, relative risks and 95\% confidence intervals as well as numbers needed to treat. The secondary outcome measures will be addressed in a similar manner. Continuous outcome measures will be compared using parametric and non-parametric tests, depending on the distribution of the data. We plan a subgroup analysis of women with diabetes type 1 and type 2 diabetes and gestational diabetes.

\section{Interim analysis}

An interim analysis will be performed after the inclusion of 150 women. This analysis will be done by an independent data and safety monitoring committee, which will not be aware of the allocation of sensor or routine control when they judge data on effectiveness. In case of 
strong effects, the safety monitoring committee can advise to stop the study. Furthermore, each SAE will be reported to the data and safety monitoring committee.

\section{Discussion}

Women with diabetes in pregnancy are at high risk for unfavourable pregnancy outcomes. Strict glycaemic control is required during pregnancy to minimize complications. After its introduction, continuous glucose monitoring has gained ground quickly in diabetes care in order to optimize glycaemic control. However, the clinical and cost-effectiveness of CGMS to improve pregnancy outcome remains to be clarified. This randomised controlled trial aims to evaluate the effect of CGMS use on pregnancy outcome in diabetic pregnancies.

\section{Abbreviations}

GA: Gestational age; CGM: Continuous glucose monitoring;

CGMS: Continuous glucose monitoring system; RCT: Randomised controlled trial; Cl: Confidence interval; RDS: Respiratory distress syndrome; BPD: Broncho pulmonal dysplasia; NEC: Necrotizing enterocolitis.

\section{Competing interests}

The authors declare that they have no competing interests.

\section{Authors' contributions}

$I M E, A F$ and BWM were involved in conception and design of the study. JHD has made substantial contributions to the design and conduction of the study. DNV, JHD, AF, BWM and IE drafted the manuscript. All authors mentioned in the manuscript are members of the GlucoMOMS-trial study group. All authors read, edited and approved the final manuscript.

\section{Acknowledgements}

This study is funded by ZonMw, a Dutch organisation for Health Research and Development. Project number 80-82310-97-11157. All researchers involved in this study: M. Kok, Department of Obstetrics and Gynaecology, Academic Medical Centre Amsterdam, Amsterdam M.C.J. Schreuder, Department of Endocrinology, Academic Medical Centre Amsterdam, Amsterdam D.J. Bekedam, Department of Obstetrics and Gynaecology, Onze Lieve Vrouwen gasthuis, Amsterdam C.B. Brouwer, Department of Endocrinology, Onze Lieve Vrouwen gasthuis, Amsterdam B.F. Fong, Department of Obstetrics and Gynaecology, Zaans Medical Centre, Zaandam A. Binnerts, Department of Endocrinology, Zaans Medical Centre, Zaandam M.H.B. Heres, Department of Obstetrics and Gynaecology, Sint Lucas Andreas Hospital, Amsterdam R. Maas, Department of Obstetrics and Gynaecology, Sint Lucas Andreas Hospital, Amsterdam B.J. Potter van Loon, Department of Endocrinology, Sint Lucas Andreas Hospital, Amsterdam J. Lenglet, Department of Obstetrics and Gynaecology, Flevo hospital, Almere N. Smit, Department of Endocrinology, Flevo hospital, Almere B.A. Braams-Lisman, Department of Obstetrics and Gynaecology, Tergooi Hospital, Hilversum E. Seebus, Department of Endocrinology, Tergooi Hospital, Hilversum E. van Beek, Department of Obstetrics and Gynaecology, Sint Antonuis Hospital, Nieuwegein I.M.M.J. Wakelkamp, Department of Endocrinology, Sint Antonuis Hospital, Nieuwegein M.A. Oudijk, Department of Obstetrics and Gynaecology, University Medical Centre, Utrecht H.W. de Valk, Department of Endocrinology, University Medical Centre, Utrecht T.E. Vogelvang, Department of Obstetrics and Gynaecology, Diakonessenhuis, Utrecht A.F. Muller, Department of Endocrinology, Diakonessenhuis, Utrecht M.E. Sanson, Department of Endocrinology, Meander Medical Centre, Amersfoort K.W. Bloemenkamp, Department of Obstetrics and Gynaecology, Leids University Medical Centre, Leiden E.J.P. de Koning, Department of Endocrinology, Leids University Medical Centre, Leiden R.P.L.M. Hoogma, Department of Endocrinology, Groene Hart Hospital, Gouda C.A. van Meir, Department of Obstetrics and Gynaecology, Groene Hart Hospital, Gouda A.H. Feitsma, Department of Obstetrics and Gynaecology, Haga Hospital, Den Haag H. van Houten, Department of Endocrinology, Haga Hospital, Den Haag
M.M. Porath, Department of Obstetrics and Gynaecology, Maxima Medical Centre, Veldhoven R.J. Erdtsieck, Department of Endocrinology, Maxima Medical Centre, Veldhoven C.M. Oirschot, Department of Obstetrics and Gynaecology, Sint Elisabeth Hospital, Tilburg W.A.C.M. Nieuwlaat, Department of Endocrinology, Sint Elisabeth Hospital, Tilburg R.JP. Rijnders, Department of Obstetrics and Gynaecology, Jeroen Bosch Hospital, Den Bosch I.P.M. Gaugler, Department of Obstetrics and Gynaecology, Jeroen Bosch Hospital, Den Bosch H. Janssen, Department of Endocrinology, Jeroen Bosch Hospital, Den Bosch J. langenveld, Department of Obstetrics and Gynaecology, Atrium Medical Centre, Heerlen R. Bianchi, Department of Endocrinology, Atrium Medical Centre, Heerlen A.J. van Loon, Department of Obstetrics and Gynaecology, Martini Hospital, Groningen K. Hoogenberg, Department of Endocrinology, Martini Hospital, Groningen B. Nij Bijvank, Department of Obstetrics and Gynaecology, Isala Hospital, Zwolle HJ.G. Bilo, Department of Endocrinology, Isala Hospital, Zwolle G.C.H. Metz, Department of Obstetrics and Gynaecology, Ikazia Hospital, Rotterdam M.G.A. Baggen, Department of Endocrinology, Ikazia Hospital, Rotterdam B.M.C. Akerboom, Department of Obstetrics and Gynaecology, Albert Schweitzer Hospital, Dordrecht R.M. Rosalie Kiewiet - kemper, Department of Endocrinology, Albert Schweitzer Hospital, Dordrecht M.D. Woiski, Department of Obstetrics and Gynaecology, University Medical Centre Sint Radboud, Nijmegen L.D. Elving, Department of Endocrinology, University Medical Centre Sint Radboud, Nijmegen R.H. Stigter, Department of Obstetrics and Gynaecology, Deventer Hospital, Deventer M.N. Gerding, Department of Endocrinology, Deventer Hospital, Deventer M.J.M. Diekman, Department of Endocrinology, Deventer Hospital, Deventer.

\section{Author details}

'Department of Obstetrics and Gynaecology, University Medical Centre Utrecht, Utrecht, the Netherlands. ${ }^{2}$ Department of Endocrinology, Academic Medical Centre Amsterdam, Amsterdam, the Netherlands. ${ }^{3}$ Department of Obstetrics and Gynaecology, Academic Medical Centre Amsterdam, Amsterdam, the Netherlands. ${ }^{4}$ Department of Obstetrics and Gynaecology, Maxima Medical Centre Veldhoven, Veldhoven, the Netherlands.

${ }^{5}$ Department of Obstetrics and Gynaecology, Meander Medical Centre Amersfoort, Amersfoort, the Netherlands.

Received: 24 October 2012 Accepted: 26 November 2012 Published: 27 December 2012

\section{References}

1. Management of diabetes from preconception to the postnatal period: summary of NICE guidance. BMJ 2008, 336:714-717.

2. Gabbe SG: Management of diabetes mellitus in pregnancy. Am J Obstet Gynecol 1985, 153:824-828

3. Hawthorne G, Robson S, Ryall EA, Sen D, Roberts SH, Ward Platt MP: Prospective population based survey of outcome of pregnancy in diabetic women: results of the northern diabetic pregnancy audit, 1994. BMJ 1997, 315:279-281.

4. Evers IM, de Valk HW, Visser GH: Risk of complications of pregnancy in women with type 1 diabetes: nationwide prospective study in the Netherlands. BMJ 2004, 328:915.

5. McLachlan K, Jenkins A, O'Neal D: The role of continuous glucose monitoring in clinical decision-making in diabetes in pregnancy. Aust N Z J Obstet Gynaecol 2007, 47:186-190.

6. Sachedina N, Pickup JC: Performance assessment of the medtronicMiniMed continuous glucose monitoring system and its use for measurement of glycaemic control in type 1 diabetic subjects. Diabet Med 2003, 20:1012-1015.

7. Langendam MW, Luijf YM, Hooft L, Devries JH, Mudde AH, Scholten RJ Continuous glucose monitoring systems for type 1 diabetes mellitus. Cochrane Database Syst Rev 2012, 1:CD008101.

8. Murphy HR, Rayman G, Lewis K, Kelly S, Johal B, Duffield K, et al: Effectiveness of continuous glucose monitoring in pregnant women with diabetes: randomised clinical trial. BMJ 2008, 337:a1680.

9. Secher AL, Ringholm L, Andersen HU, Damm P, Mathiesen ER: The effect of real-time continuous glucose monitoring in diabetic pregnancy - a randomised controlled trial. Diabetologia 2012, 55(SUPPL 1):S40.

10. Jensen DM, Damm P, Moelsted-Pedersen L, Ovesen P, Westergaard JG, Moeller $\mathrm{M}$, et al: Outcomes in type 1 diabetic pregnancies: a nationwide, population-based study. Diabetes Care 2004, 27:2819-2823. 
11. Clausen TD, Mathiesen E, Ekbom P, Hellmuth E, Mandrup-Poulsen T, Damm P: Poor pregnancy outcome in women with type 2 diabetes. Diabetes Care 2005, 28:323-328.

12. Persson M, Norman M, Hanson U: Obstetric and perinatal outcomes in type 1 diabetic pregnancies: a large, population-based study. Diabetes Care 2009, 32:2005-2009

13. Ferrara $A$, Kahn $H S$, Quesenberry $C P$, Riley $C$, Hedderson MM: An increase in the incidence of gestational diabetes mellitus: Northern California, 1991-2000. Obstet Gynecol 2004, 103:526-533.

14. Getahun D, Nath C, Ananth CV, Chavez MR, Smulian JC: Gestational diabetes in the United States: temporal trends 1989 through 2004. Am J Obstet Gynecol 2008, 198:525.

15. Rijpert M, Evers IM, de Vroede MA, de Valk HW, Heijnen CJ, Visser GH: Risk factors for childhood overweight in offspring of type 1 diabetic women with adequate glycemic control during pregnancy: nationwide follow-up study in the Netherlands. Diabetes Care 2009, 32:2099-2104.

16. Rijpert M, Evers IM, de Valk HW, de Vroede MA, Tersteeg-Kamperman M Heijnen CJ, et al: Cardiovascular and metabolic outcome in 6-8 year old offspring of women with type 1 diabetes with near-optimal glycaemic control during pregnancy. Early Hum Dev 2011, 87:49-54.

17. Sparano S, Ahrens W, De HS, Marild S, Molnar D, Moreno LA, et al: Being macrosomic at birth is an independent predictor of overweight in children: results from the IDEFICS study. Matern Child Health J 2012, epub Sept.

18. Hermanides J, Vriesendorp TM, Bosman RJ, Zandstra DF, Hoekstra JB, Devries JH: Glucose variability is associated with intensive care unit mortality. Crit Care Med 2010, 38:838-842.

19. Oostenbrink JB, Koopmanschap MA, Rutten FF: Standardisation of costs: the dutch manual for costing in economic evaluations. PharmacoEconomics 2002, 20:443-454.

20. Clements KM, Barfield WD, Ayadi MF, Wilber N: Preterm birth-associated cost of early intervention services: an analysis by gestational age. Pediatrics 2007, 119:e866-e874.

doi:10.1186/1471-2393-12-164

Cite this article as: Voormolen et al: Effectiveness of continuous glucose monitoring during diabetic pregnancy (GlucoMOMS trial); a randomised controlled trial. BMC Pregnancy and Childbirth 2012 12:164.

\section{Submit your next manuscript to BioMed Central and take full advantage of:}

- Convenient online submission

- Thorough peer review

- No space constraints or color figure charges

- Immediate publication on acceptance

- Inclusion in PubMed, CAS, Scopus and Google Scholar

- Research which is freely available for redistribution 